\title{
Article
}

\section{Novel stress corrosion testing method for high-strength steels}

A. Renata. Latypova*, A. Timo Kauppi, B. Saara Mehtonen, C. Hannu Hänninen, A. David Porter, A. Jukka Kömi

Renata Latypova

University of Oulu, Faculty of Technology, Materials and Production Engineering, POB 4200, 90014 Oulu, Finland

renata.latypova@oulu.fi

Timo Kauppi

University of Oulu, Faculty of Technology, Materials and Production Engineering, POB 4200, 90014 Oulu, Finland

Saara Mehtonen

SSAB, P.O. Box 93, 92101 Raahe, Finland

\section{Hannu Hänninen}

Aalto University School of Engineering, Department of Mechanical Engineering, P.O. Box 14200, FI-00076

David Porter

University of Oulu, Faculty of Technology, Materials and Production Engineering, POB 4200, 90014 Oulu, Finland

Jukka Kömi

University of Oulu, Faculty of Technology, Materials and Production Engineering, POB 4200, 90014 Oulu, Finland 


\section{WILEY-VCH}

This paper presents a novel TFT (Tuning Fork Test) stress corrosion testing method, which was developed for classifying martensitic high-strength steels. The novel method was developed by applying finite element calculations to optimize a tuning fork geometry to enable accurate stress adjustment with simple inexpensive equipment. Different steels were exposed to cathodic hydrogen charging conditions with various elastic tensile stress levels that were achieved by displacement control. All steels exhibited hydrogen-induced stress corrosion cracking after exceeding a material-specific threshold stress level that decreased linearly with increasing hardness.

Keywords: High-strength steel, hydrogen embrittlement, pitting corrosion, stress corrosion cracking

\section{Introduction}

Stress corrosion cracking (SCC) is a complex failure mode requiring the presence of three factors: a susceptible material, tensile stress, and an alloy-specific corrosion environment. [1] The biggest concern with SCC is its unforeseeable nature, which can cause unpredictable and catastrophic failures. [2] This phenomenon is a major problem for many industries since it can lead to the brittle fracture of a normally ductile material. [3,4]

SCC susceptibility of high-strength steels usually increases with increasing strength. [5] For these steels, hydrogen embrittlement (HE) is generally considered to be the predominant SCC mechanism. [1] In case of SCC of high-strength steels, SCC and HE are combined into a transition form of hydrogen-induced stress corrosion cracking (HISCC). [6] HISCC occurs in the presence of active corrosion, usually pitting or crevice corrosion, in almost any acidic environment that produces hydrogen as a by-product of surface corrosion by cathodic reactions. [7] Reduced to its atomic form, hydrogen absorbs into the material 


\section{WILEY-VCH}

diffusing through the crystal lattice to regions of high triaxial tensile stress. [5,8,9] When the material is stressed in tension, the diffusivity of hydrogen increases due to the expansion of the crystal lattice. [2] Hydrogen atoms may induce reduction in the cohesive strength of atomic bonds, thereby causing fracture to occur at reduced stress levels. [2,10]

High-strength steels are employed in many engineering applications but their use is restricted inevitably due to their susceptibility to SCC. [11] The constant development of stronger and tougher alloys increases the need to determine their degree of susceptibility, and to assess the risks of SCC in a given application. [1] Therefore, test methods for predicting and measuring SCC susceptibility are essential. [4]

The aim of this research was to develop a suitable testing method for ranking highstrength steels according to their SCC susceptibility. Most SCC problems in industrial applications are related to residual stresses, which develop during, e.g. heat treatment, plastic deformation, or welding. [1] Therefore, constant displacement self-stressed loading was selected to reflect the residual stresses [12], which are always present in high-strength steels due to their microstructure.

The many available testing methods for SCC are not practical due to limited stress control with standard geometries or to the requirement of complex test equipment for application of loads. Normally, the most common types of smooth constant-displacement specimens are bent-beam $[13,14]$, C-ring $[15,16]$ and U-bend $[17,18]$ and self-loaded tensile specimens[19,20]. [21] These shapes can be achieved through forming/bending, which can be challenging to perform identically. After shaping, the stress distribution is modified and afterwards when displacement is retained with jigs, there is a risk of spring back, overloading, distortion, misalignment and stress relaxation with time. On the other hand, the slow strain rate test (SSRT) [22,23] and the linearly increasing stress test (LIST) [24,25] do not require any additional forming of the tensile specimens. These tests produce a lot more versatile 


\section{WILEY-VCH}

results, but the testing procedure requires specialized apparatus, which is relatively expensive compared to the self-stressed constant-displacement SCC testing methods.

The technical implementation of the TFT was aimed to be simple yet effective, providing easily interpreted results with a low-cost equipment. The new geometry eliminated stress control issues and the test specimens did not require any bending prior to the testing. The application of stress was optimized with FEM models and a new hand adjustable clamping device. Therefore, the TFT is a significant improvement over traditional constantdisplacement tests. Also, TFT is cheaper to perform and more easily interpreted than the SSRT or LIST.

\section{Experimental procedures}

\subsection{Test material and specimens}

All experiments were carried out with test specimens manufactured from directquenched, abrasion-resistant steel grades with martensitic microstructures. The nominal hardness levels of the test materials were 450, 500 and $600 \mathrm{HBW}$. Table 1 presents the chemical compositions and mechanical properties as provided by the steel supplier.

All used materials were $6 \mathrm{~mm}$ thick hot-rolled strip products. The strips were cut into sheets, followed by machining of both surfaces until the final thickness of $5 \mathrm{~mm}$ was achieved. Afterwards, the TFT specimens were wire electrical discharge machined (WEDM) such that the longitudinal dimension was parallel to the rolling direction of the sheets. WEDM was selected due to its ability to produce complex parts with high dimensional accuracy. [26] 


\section{WILEY-VCH}

The specimen design was based on the "tuning fork" geometry, which has been used, for example, in the SCC testing of aluminium alloys. [27]

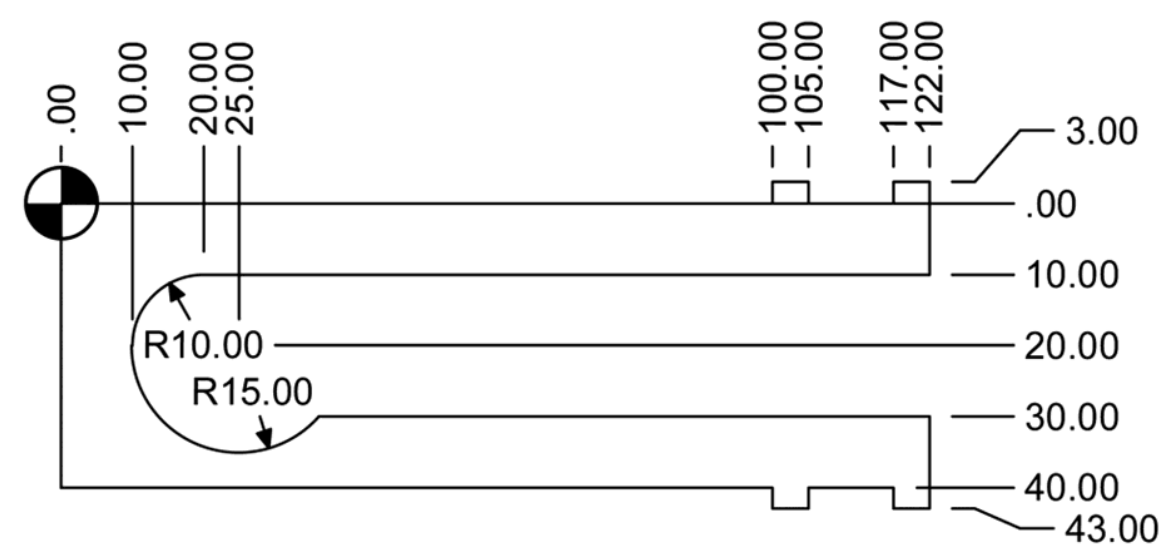

Figure 1 presents the modified geometry used. The main changes compared to the old geometry concerned the symmetry of the fork, which ensured that cracking occurred only on the narrower side of the specimen.

\subsection{Electrochemical hydrogen charging}

Constant displacement tests were performed at room temperature under cathodic hydrogen charging conditions (VersaSTAT3 Potentiostat) using a $0.1 \mathrm{M} \mathrm{H}_{2} \mathrm{SO}_{4}$ electrolyte together with a constant current density of $10 \mathrm{~mA} / \mathrm{cm}^{2}$. Thiourea $\mathrm{CH}_{4} \mathrm{~N}_{2} \mathrm{~S}(5 \mathrm{~g} / \mathrm{l})$ was added to the electrolyte as a hydrogen recombination poison to increase hydrogen absorption. The anode was a mixed metal oxide (MMO) electrode mesh with titanium base material and an oxide coating. [28] The threshold stress level $\left(\sigma_{\mathrm{th}}\right)$ was measured in this environment for each steel grade to evaluate their susceptibility to SCC.

All tests were recorded or monitored with a webcam (Creative Live! Cam IP SmartHD). The webcam was enhanced by adding an accessory magnifying lens, which produced a high-resolution image. In addition to the recordings obtained, the use of a wireless webcam enabled live stream during the testing from a mobile device or a computer screen. 


\section{WILEY-VCH}

\subsubsection{Sample preparation}

Prior to the testing, specimens were polished, ultrasonically cleaned for $5 \mathrm{~min}$ and subsequently taped and stressed with a specially designed clamp. The clamp prevented the specimen arms from moving crosswise, allowing only inward movement, which was used to create the elastic tensile stress needed.

Based on the tensile testing results, specific FEM models were designed with Abaqus for each steel grade. Figure 2 demonstrates the narrow stress concentration zones during clamping with red colour highlighting the high-stress concentration areas.

The simulation results enabled the adjustment of the desired elastic stress with different arm displacements using a clamping screw (X8CrNiS18-9) with an accuracy of +/$0.01 \mathrm{~mm}$. The measurement of displacement was conducted with a digital slide gauge when the screw was engaged in the narrower side of the specimen arm. The clamping arrangement is presented in Figure 3.

The only mechanically polished specimen surface was the outer part of the narrower arm, which is the only location with a concentration of tensile stress. Mechanical polishing was made with a TransPol-5 (Struers) polishing machine, using 240, 600 and 1200 grit discs. The surface roughness achieved was approximately $0.1 \mu \mathrm{m}\left(\mathrm{R}_{\mathrm{a}}\right)$ and it was measured with Mitutoyo Surftest SJ-301 equipment. The other specimen surfaces were gently polished by hand with 1200 grit abrasive paper to remove additional substances, which could contaminate the electrolyte.

During hydrogen charging, only a part of the specimen was exposed to the electrolyte by isolating the other areas with Teflon tape as illustrated in

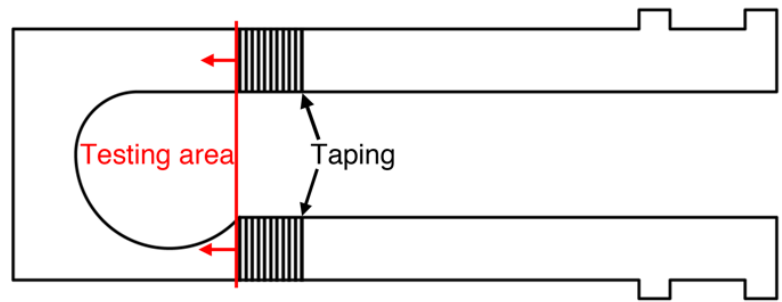




\section{WILEY-VCH}

Figure 4. During the testing, the surface of the electrolyte was approximately at the level of the middle part of the tape.

\subsubsection{Threshold stress $\left(\sigma_{t h}\right)$}

The threshold stress level for SCC of the test materials was determined using the binary search procedure illustrated in Figure 5 as described in the standard for stress corrosion testing SFS-EN ISO 7539-1. [29]

The 5-step procedure started with a first test at a stress level of $R_{m} / 2$ and then continued further based on the result. If the test result was fracture (F), the second step was a test at $\mathrm{R}_{\mathrm{m}} / 4$. If there was no fracture (NF), the second step was at $3 \mathrm{R}_{\mathrm{m}} / 4$ and so on until the end of the flow chart. After reaching the final, fifth step, additional testing was conducted until the $25 \mathrm{MPa}$ stress difference between $\mathrm{F}$ and NF results was established. Figure 6 demonstrates how the confirmation of an $\mathrm{F}$ result was monitored during hydrogen charging. The maximum testing time was $24 \mathrm{~h}$, which was employed to verify the absence of cracking.

\subsubsection{Metallography}

After hydrogen charging tests, the specimens were rinsed with distilled water and ultrasonically cleaned in ethanol for $5 \mathrm{~min}$. The selected samples were prepared for microscopic examination and studied with a light optical microscope or a laser scanning confocal microscope or both.

Fracture surfaces were investigated in order to detect the crack initiation sites and to identify the crack propagation modes. Fracture surfaces were observed and analysed with a FEI Guenta 450 FEG field-emission scanning electron microscope (FESEM) equipped with Thermo Nora System 312E energy-dispersive X-ray spectroscope (EDS) analyser. 


\section{WILEY-VCH}

\section{Experimental results and discussion}

\subsection{Evidence of SCC}

The specimen is cathodically protected during cathodic hydrogen charging while acting as a cathode. Pitting corrosion was, however, identified after hydrogen charging on all testing area surfaces as presented in Figure 7. Thus, the specimens were not immune to corrosion in sulphuric acid environment. The sulphuric acid is known to cause SCC in the mining industry [30], e.g. the SCC of rock bolts [31,32] in Australian mines.

Surface damage, such as hydrogen blisters are known to appear during electrochemical hydrogen charging with excessive current densities or charging times. [33-35] Visual inspection of hydrogen charged specimen surfaces did not reveal the occurrence of hydrogeninduced blisters on any of the investigated steel grades.

Corrosion pits are surface defects and they are common sites for stress corrosion initiation. [5] Corrosion pit provides a local stress concentration with favourable electrochemical conditions for crack initiation. [36] The emanation of microcracks from corrosion pits is considered as the most important indication of HISCC. [6] This type of SCC initiation process was ascertained for the smallest microscopically visible cracks after hydrogen charging, as can be seen in Figure 8. The depth of most of the cracks was much larger than that of the corrosion pits making it difficult to identify their initiation site.

Different sulphide inclusions that are present in the steel can play a role in pitting corrosion nucleation depending on their type, density and distribution. Pitting corrosion resistance of steel increases with the decreasing amount of sulphide solubility in the environment, i.e. as follows: $\mathrm{CaS}<\mathrm{MnS}<\mathrm{CrS}<\mathrm{TiS}<\mathrm{CeS}$. In terms of pitting corrosion, sulphides cause deposits to form on the passive film around the sulphide inclusions, thereby locally reducing pitting corrosion resistance, and eventually leading to pit nucleation. [37-39] 


\section{WILEY-VCH}

Therefore, cracks may have initiated from sulphide inclusions on the steel surface, but due to their small size, it was not possible to confirm if this was the case.

Depending on the alloy, microstructure and service environment, stress corrosion cracking may appear either with intergranular (IG) or transgranular (TG) morphology. $[10,40,41]$ Both morphologies were observed after the hydrogen charging testing (Figure 9) together with branching secondary cracks (Figure 10). The branching cracks are considered to be the direct evidence of SCC since no other type of metallurgical failure mechanism produces this kind of cracking pattern. [7]

One factor, which favours the SCC failure mechanism is the presence of corrosion products on the fracture surface. [40] The EDS analyses revealed sulphur-containing corrosion products on the fracture surfaces, which presumably originate from the sulphuric acid electrolyte (Table 2). Fracture surfaces of the investigated steel grades were brittle, which is typical for SCC mechanism of fracture. [40] The investigated fracture surfaces manifested transgranular fractures with a number of secondary cracks and intergranular areas, that increased with the increasing steel hardness. The FESEM/SE images of mostly transgranular brittle fracture surfaces are presented in Figure 11.

\subsection{SCC susceptibility evaluation}

TFT produces a favourable condition for SCC of high-strength steels by simultaneously combining tensile stress, hydrogen absorption and a corrosive environment. The test procedure was meant to replicate the environmental conditions, which in service may lead to SCC of high-strength steels in an accelerated manner. The metallographic examinations confirmed the occurrence of SCC. 


\section{WILEY-VCH}

There are different criteria for interpreting SCC results, such as time to failure $\left(\mathrm{t}_{\mathrm{f}}\right)$ and threshold stress level $\left(\sigma_{\mathrm{th}}\right)$. However, $\mathrm{t}_{\mathrm{f}}$ can be misleading when used for the comparison of alloys with different strength levels and fracture toughnesses. The determination of $t_{\mathrm{f}}$ is operator dependent since what constitutes sufficient crack depth and the definition of the test duration are ambiguous. More information can be obtained by using a range of applied stress leading to the estimation of the threshold stress level. [1] Therefore, the environmental threshold stress level is considered to be a suitable testing parameter for assessing susceptibility to SCC. [42] However, use of data in the design of structural components should be treated with caution.

Usually, $\sigma_{\text {th }}$ is taken as the average of the lowest stress at which stress corrosion cracking is observed and the highest stress below which SCC did not occur. Determined $\sigma_{\text {th }}$ can be used to estimate the environmental maximum stress, which may then be applied in service without SCC failure. It is important to acknowledge that the results are strongly influenced by the selected testing method, specimen geometry, environment and other mechanical and environmental aspects controlling crack initiation and propagation times. Therefore, the concept of threshold stress must be qualified with regard to the test conditions and the level of statistical significance and not be considered as a material property. [1]

In this study, the no-fracture result was established 3 times for each steel grade, in addition to other tests confirming the lowest fracture stress. Threshold stress was then determined by taking the average value from fracture (F) and no-fracture (NF) results, which are given in Table 3.

After each NF result, the clamp relaxation was measured as final arm distance and then compared to the original set-up. The relaxation of the clamp arrangement for NF results varied between $0.01-0.1 \mathrm{~mm}$, which corresponds to $3-30 \mathrm{MPa}$ stress change. 


\section{WILEY-VCH}

The threshold stress level is not a good parameter for steel ranking. However, when it is presented as percentage of the tensile strength, it becomes a material parameter in a specific testing environment. This relative threshold stress level $\left(\sigma_{\mathrm{th}} / \mathrm{R}_{\mathrm{m}}\right)$ enables the ranking of different steel grades. Since tensile and hardness properties correlate with each other [43], material hardness was selected as a second parameter for steel ranking.

The test results confirmed that $\sigma_{\mathrm{th}} / \mathrm{R}_{\mathrm{m}}$ decreases as the hardness level increases. In other words, the fracture in the harder steel occurs with a lower stress compared to steel with lower hardness. Since the environment was otherwise the same, the harder steel proved to be more susceptible to SCC at lower relative threshold stress level as well as at lower absolute stress level. The $\mathrm{R}^{2}$ value of $94 \%$ also indicates that there is a strong relationship between the different hardness levels and their $\sigma_{\mathrm{th}} / \mathrm{R}_{\mathrm{m}}$ in this specific hardness range. The relationship of hardness and $\sigma_{\mathrm{th}} / \mathrm{R}_{\mathrm{m}}$ is summarized in Figure 12. However, more data is required to establish what kind of relationship exists between hardness and $\sigma_{\mathrm{th}} / \mathrm{R}_{\mathrm{m}}$, for example, over a wider range of hardness values.

Depending on the steel grade, the $24 \mathrm{~h}$ period was approximately $3-12$ times longer compared to the time-to-fracture result achieved with $25 \mathrm{MPa}$ higher stress. Therefore, $24 \mathrm{~h}$ was considered an appropriate testing time to confirm the no-fracture result.

Currently, the designed TFT test conditions are applicable for high-strength steels, but the modified tuning fork geometry shows potential for other applications too. In the future, the geometry can be applied for testing other steels and phenomena making it more versatile. The TFT can be successfully used for characterizing and ranking high-strength steels in moderate time periods, e.g. of one week per steel grade.

\section{Conclusions}




\section{WILEY-VCH}

A novel tuning fork test (TFT) was developed for evaluating and ranking the susceptibility of high-strength steels to stress corrosion cracking. In this testing method, specimens with a modified tuning fork geometry are subjected to various applied elastic tensile stress levels via an applied constant displacement and exposed to a corrosive hydrogen charging environment. Testing was conducted at ambient temperature with an electrolyte of $0.1 \mathrm{M} \mathrm{H}_{2} \mathrm{SO}_{4}+5 \mathrm{~g} / \mathrm{l}$ thiourea using a constant cathodic current density of $10 \mathrm{~mA} / \mathrm{cm}^{2}$. The test materials included three direct-quenched abrasion-resistant steel grades with nominal hardness levels of 450, 500 and $600 \mathrm{HBW}$. The relative environmental threshold stress level $\left(\sigma_{\mathrm{th}} / \mathrm{R}_{\mathrm{m}}\right)$ for SCC was examined as a function of material hardness. The following conclusions can be drawn:

- Cathodic hydrogen charging in dilute sulphuric acid provides a favourable environment for SCC testing of high-strength steels. The environment combines corrosion and hydrogen absorption, which together with constant tensile stress are the three main factors in HISCC.

- The developed constant displacement TFT produces reliable results with good reproducibility if the elastic stress is strictly controlled and the clamp relaxation is minor.

- Relative threshold stress level $\left(\sigma_{\mathrm{th}} / \mathrm{R}_{\mathrm{m}}\right)$ for SCC is suitable for comparison and ranking of high-strength steels in specified test conditions based on their hardness properties. Over the hardness range $450-600 \mathrm{HBW}$, both $\sigma_{\mathrm{th}}$ and $\sigma_{\mathrm{th}} / \mathrm{R}_{\mathrm{m}}$ for the studied steels decrease with the increasing hardness. 


\section{WILEY-VCH}

- $\quad$ Measured $\sigma_{\mathrm{th}} / \mathrm{R}_{\mathrm{m}}$ levels were $19.6 \%, 13.1 \%$ and $7.8 \%$, respectively, for 450,500 and $600 \mathrm{HBW}$ steel grades.

\section{Acknowledgements}

This research was supported by SSAB Europe Oy. The authors wish to thank the technical staff from the Materials and Production Engineering unit at the University of Oulu for their help with the experiments and sample preparation. The authors also acknowledge the facilities and technical assistance of the Lapland University of Applied Science where most of the metallographic work took place. Finally, the authors are grateful for the preliminary work with TFT carried out by Alexander Chernyaev in cooperation with SSAB Europe Oy.

\section{References}

[1] R.H. Jones, Stress-corrosion cracking, ASM International, Materials Park, Ohio, 1992.

[2] G. Brandal, Y.L. Yao, J. Eng. Ind. 2017, 139, 081015.

[3] D.J. Wulpi, Understanding how components fail, ASM International, Materials Park, Ohio, 1999.

[4] M. Henthorne, Corrosion. 2016, 72, 1488.

[5] R.A. Cottis, Stress corrosion cracking - guides to good practice in corrosion control, The National Physical Laboratory, Teddington, Middlesex, 2000.

[6] J. Woodtli, R. Kieselbach, Eng. Failure Anal. 2000, 7, 427.

[7] R. Heidersbach, Metallurgy and corrosion control in oil and gas production, John 


\section{WILEY-VCH}

Wiley \& Sons, Inc., Hoboken, New Jersey, 2011.

[8] ASM handbook, Volume 11, ASM International, Materials Park, Ohio, 2002.

[9] W.D. Callister, D.G. Rethwisch, Materials science and engineering, John Wiley \& Sons, Inc., Hoboken, New Jersey, 2014.

[10] R.W. Hertzberg, R.P. Vinci, J.L. Hertzberg, Deformation and fracture mechanics of engineering materials, John Wiley \& Sons, Inc., Hoboken, New Jersey, 2013.

[11] C. Wen, M. Yu, S. Li, X. Li, J. Liu, Int. J. Electrochem. Sci. 2014, 9, 5803.

[12] ASM handbook, Volume 13A, ASM International, Materials Park, Ohio, 2003.

[13] ASTM G39-99, Standard practise for preparation and use of bent-beam stresscorrosion test specimens, 1999.

[14] SFS-EN ISO 7539-2, Corrosion of metals and alloys. Stress corrosion testing. Part 2: preparation and use of bend-beam specimen, 1995.

[15] ASTM G38-01, Standard practice for making and using C-ring stress-corrosion test specimens, 2001.

[16] SFS-EN ISO 7539-5, Corrosion of metals and alloys. Stress corrosion testing. Part 5: preparation and use of $C$-ring specimens, 1989.

[17] ASTM G30-97, Standard practice for making and using U-bend stress-corrosion test specimens, 2016.

[18] SFS-EN ISO 7539-3, Corrosion of metals and alloys. Stress corrosion testing. Part 3: preparation and use of U-bend specimens, 1995.

[19] ASTM G49-85, Standard practice for preparation and use of direct tension stresscorrosion test specimens, 2011.

[20] SFS-EN ISO 7539-4, Corrosion of metals and alloys. Stress corrosion testing. Part 4: preparation and use of uniaxially loaded tension specimens, 1989.

[21] W. Dietzel, A. Turnbull, Stress Corrosion Cracking, GKSS report 2007/15, 2007. 


\section{WILEY-VCH}

[22] ASTM G129-00, Standard practice for slow strain rate testing to evaluate the susceptibility of metallic materials to environmentally assisted cracking, 2000.

[23] SFS-EN ISO 7539-7, Corrosion of metals and alloys. Stress corrosion testing. Part 7: method for slow strain rate testing, 2005.

[24] A. Atrens, C.C. Brosnan, S. Ramamurthy, A. Oehlert, I.O. Smith, Meas. Sci. Technol. 1993, 4, 1281.

[25] S. Ramamurthy, W.M.L. Lau, A. Atrens, Corros. Sci. 2011, 53, 2419.

[26] K.H. Ho, S.T. Newman, S. Rahimifard, R.D. Allen, Int. J. Mach. Tool. Manu. 2004, $44,1247$.

[27] DIN 50908, Testing the resistance of wrought aluminium alloys to stress corrosion cracking, 1993.

[28] A. Chernyaev, MSc thesis, Aalto University, Finland, 2017.

[29] SFS-EN ISO 7539-1, Corrosion of metals and alloys. Stress corrosion testing. Part 1: general guidance on testing procedures, 2012.

[30] ASM handbook, Volume 13C, ASM International, Materials Park, Ohio, 2006.

[31] E. Gamboa, A. Atrens, Eng. Failure Anal. 2003, 10, 521.

[32] E. Villalba, A. Atrens, Eng. Failure Anal. 2009, 16, 164.

[33] G. Mertens, L. Duprez, B.C. De Cooman, M. Verhaege, Adv. Mat. Res. 2007, 15-17, 816.

[34] D.P. Dunne, D. Hejazi, A.A. Saleh, A.J. Haq, A. Calka, E. V. Pereloma, Int. J. Hydrogen Energy. 2016, 41, 12411.

[35] D. Pérez Escobar, C. Miñambres, L. Duprez, K. Verbeken, M. Verhaege, Corros. Sci. 2011, 53, 3166 .

[36] S. Ramamurthy, A. Atrens, Corros. Rev. 2013, 31, 1.

[37] M. Philippe, Corrosion mechanisms in theory and practice, CRC Press, Boca Raton, 
Florida, 2011.

[38] G. Wranglen, Corros. Sci. 1974, 14, 331.

[39] Z. Szklarska-Smialowska, E. Lunarska, Mater. Corros. 1981, 32, 478.

[40] N. Eliaz, A. Shachar, B. Tal, D. Eliezer, Eng. Failure Anal. 2002, 9, 167.

[41] ASM Handbook, Volume 11, ASM International, Materials Park, Ohio, 2002.

[42] T. Raja, V.S. Shoji, Stress corrosion cracking, Woodhead publishing, Sawston, Cambridge, 2011.

[43] ISO 18265, Metallic materials. Conversion of hardness values, 2004.

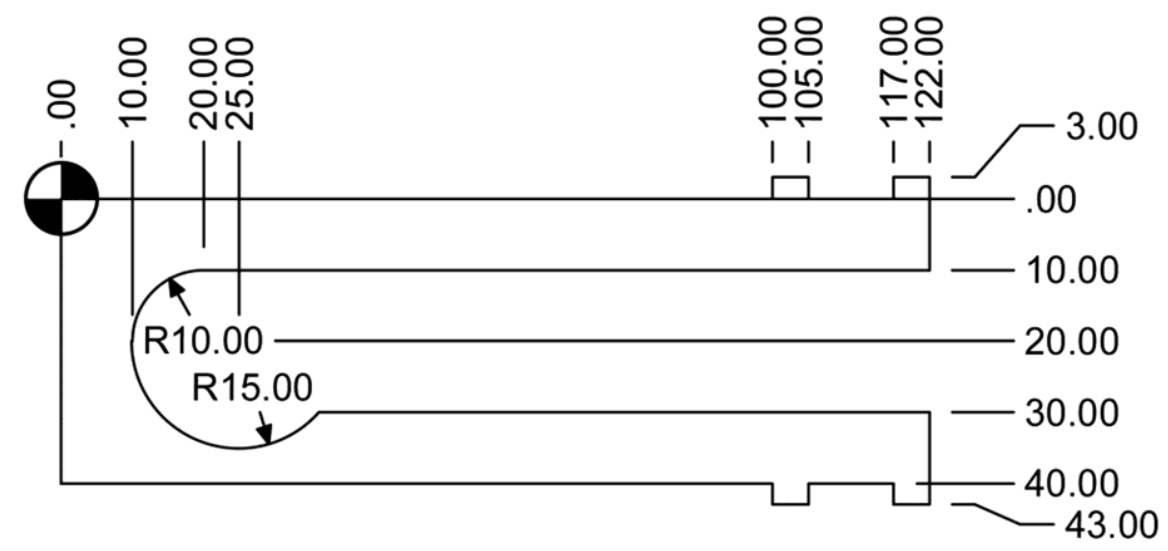

Figure 1. Illustration of the modified tuning fork specimen. Dimensions are in mm. Specimen thickness is $5 \mathrm{~mm}$. 


\section{WILEY-VCH}

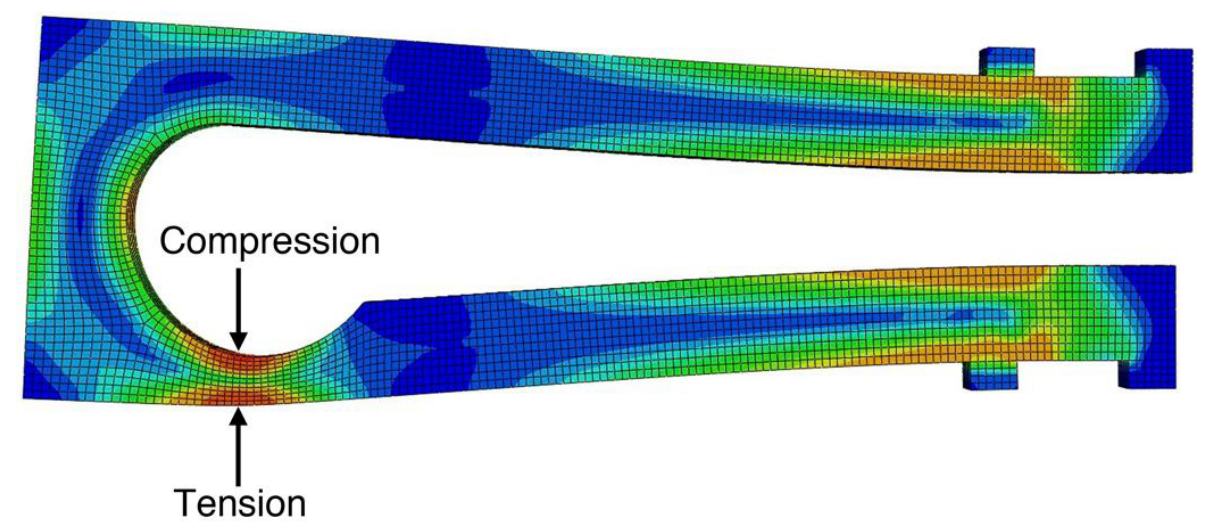

Figure 2. Stress state simulation of the clamped specimen. Red colour represents the highstress regions, which change gradually to blue as the stress decreases.

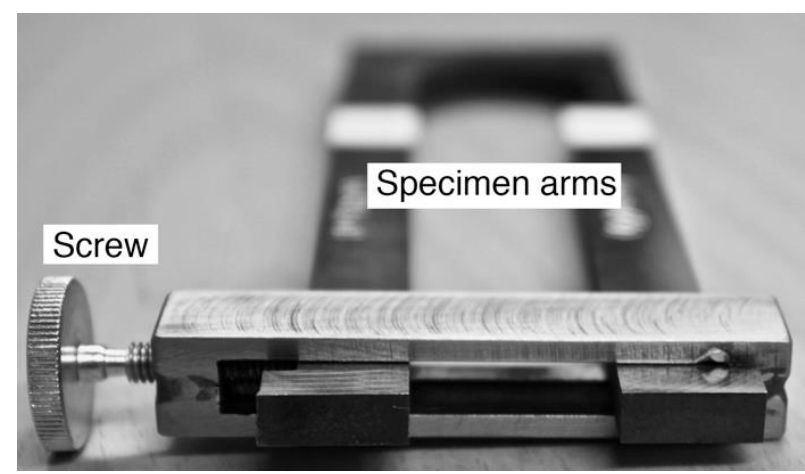

Figure 3. Clamping arrangement with screw adjusting the separation of the arms.

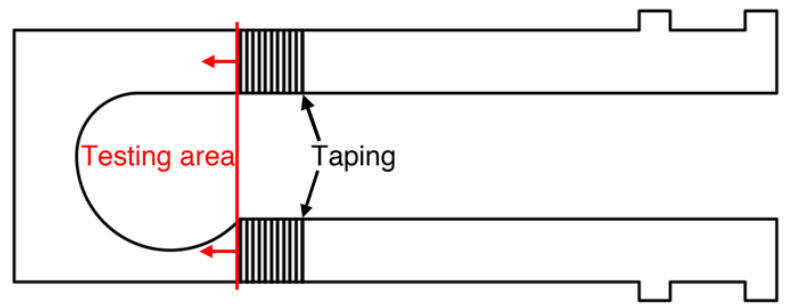

Figure 4. Schematic of testing area of the specimen separated by tape.

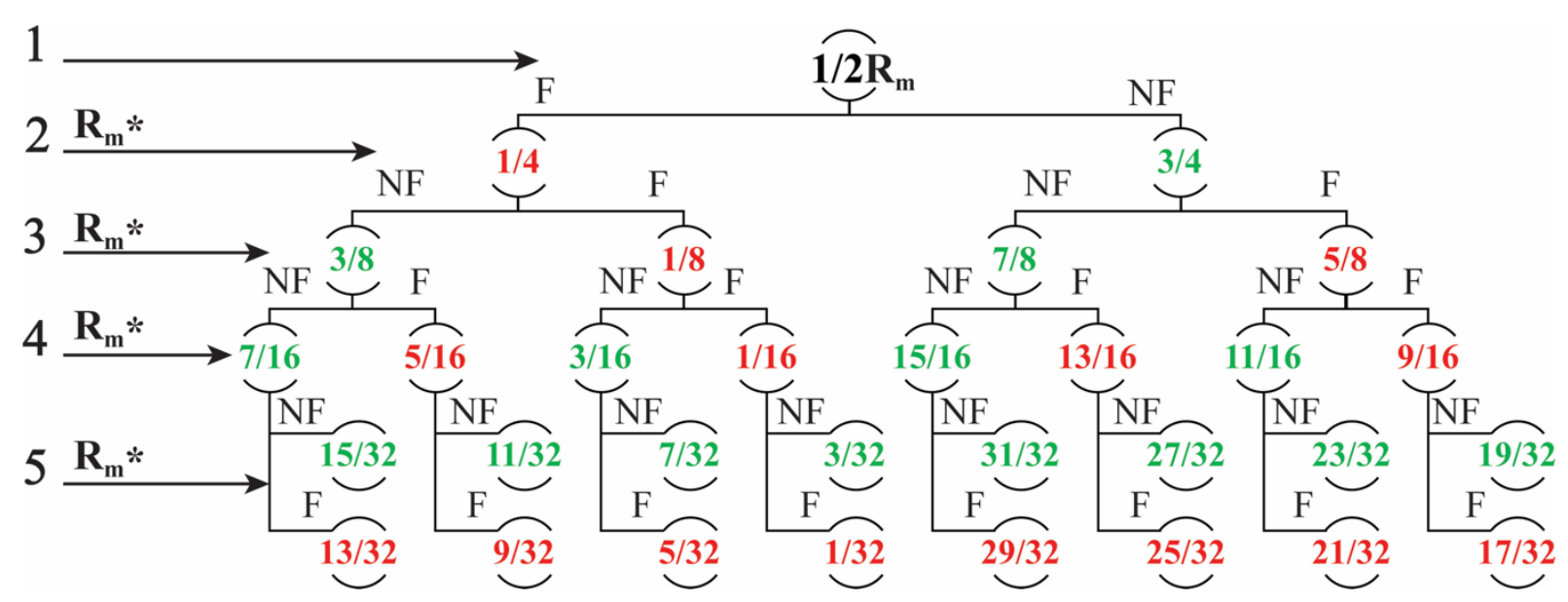




\section{WILEY-VCH}

Figure 5. Binary search procedure for threshold stress determination. [modified from 29] $R_{m}$ represents tensile strength, $\mathrm{F}=$ fracture and $\mathrm{NF}=$ no fracture.
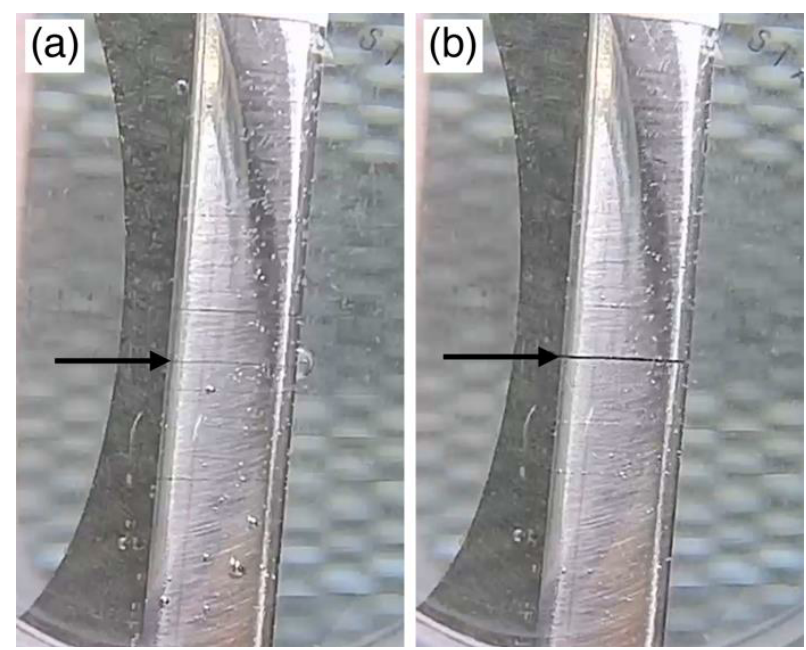

Figure 6. Camera view of high tensile stress region of the specimen during hydrogen charging. (a) before and (b) after fracture.

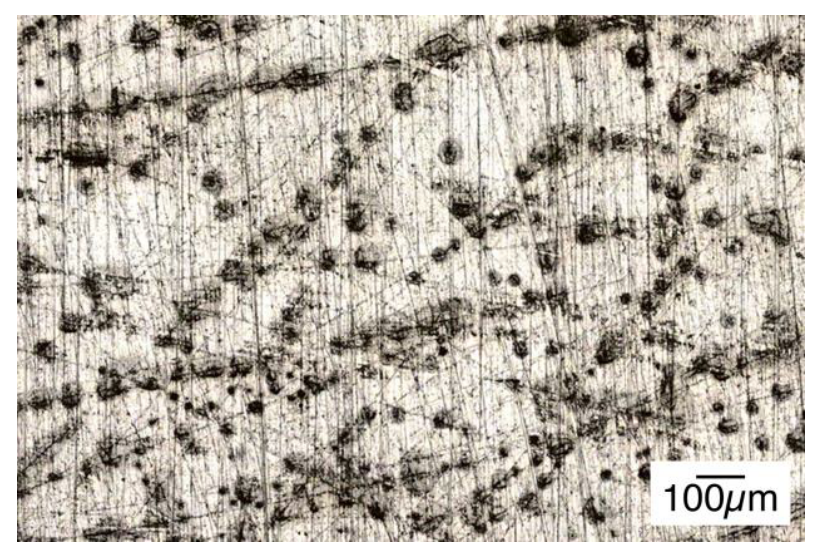

Figure 7. Pitting corrosion on the specimen surface after hydrogen charging. Laser scanning confocal microscope image.

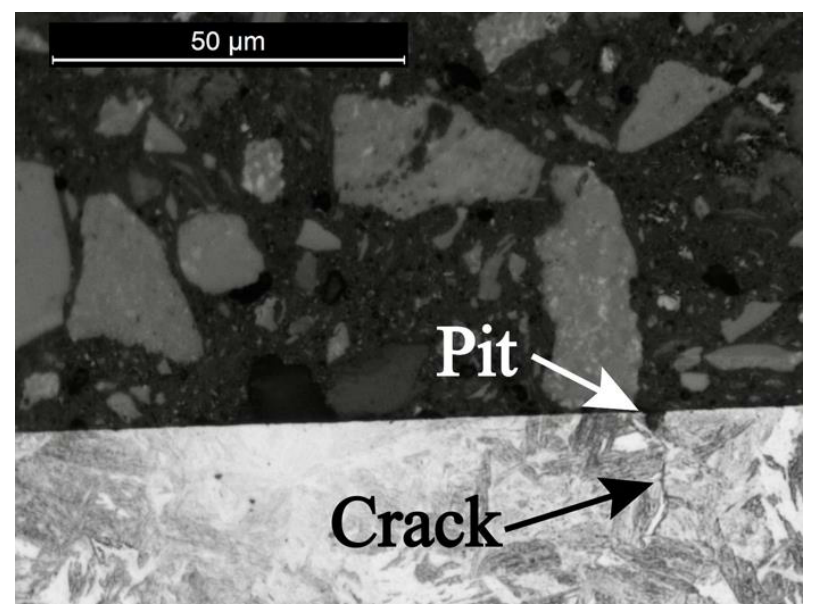




\section{WILEY-VCH}

Figure 8. Crack initiation from a corrosion pit, observed with a light optical microscope.

Etching with $2 \%$ nital solution.

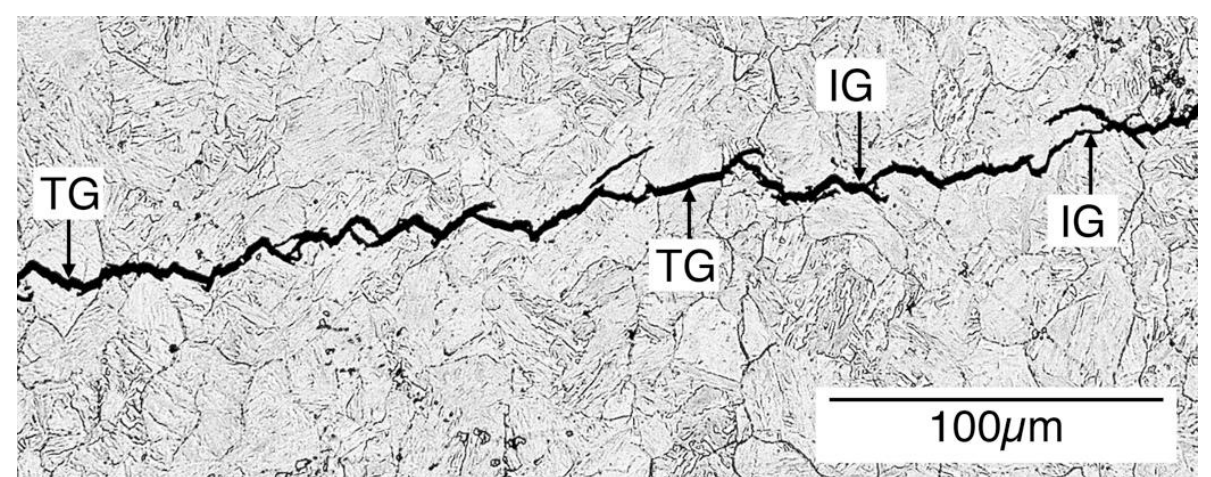

Figure 9. An example of transgranular (TG) and intergranular (IG) crack propagation in a 450

HBW steel specimen. Etching with picric acid.

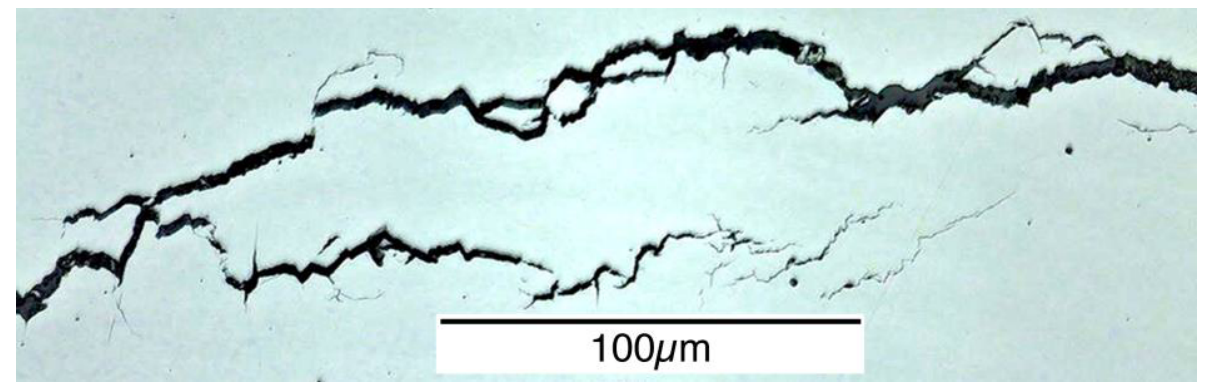

Figure 10. An example of branching stress corrosion cracks in a $600 \mathrm{HBW}$ specimen.
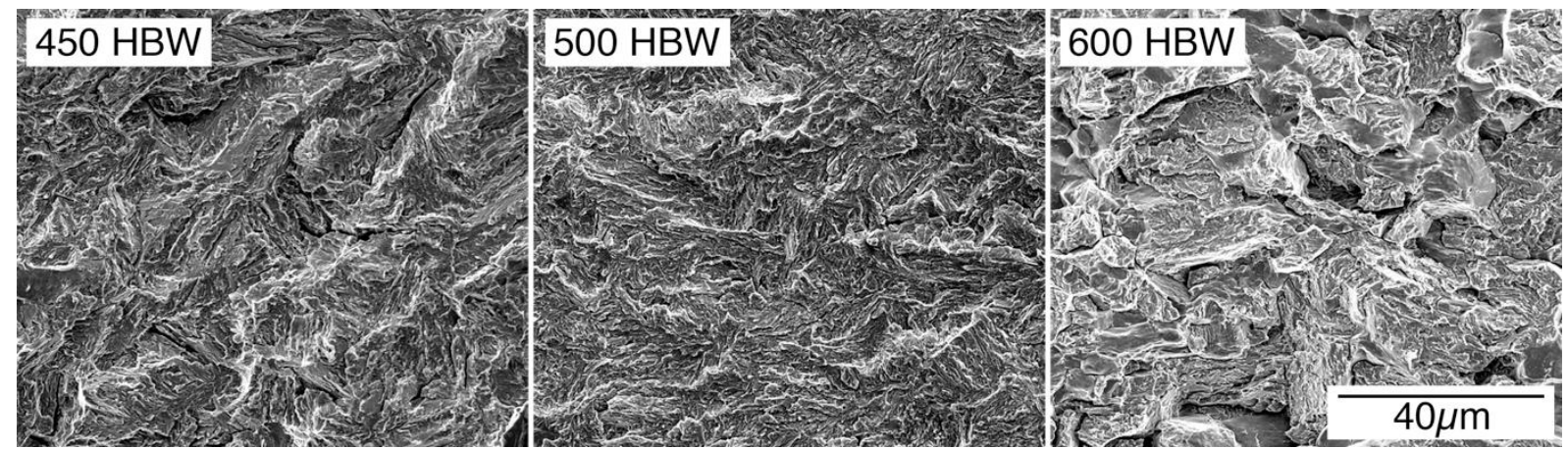

Figure 11. FESEM/SE images of mostly transgranular brittle fracture surfaces of the three tested steel grades. 


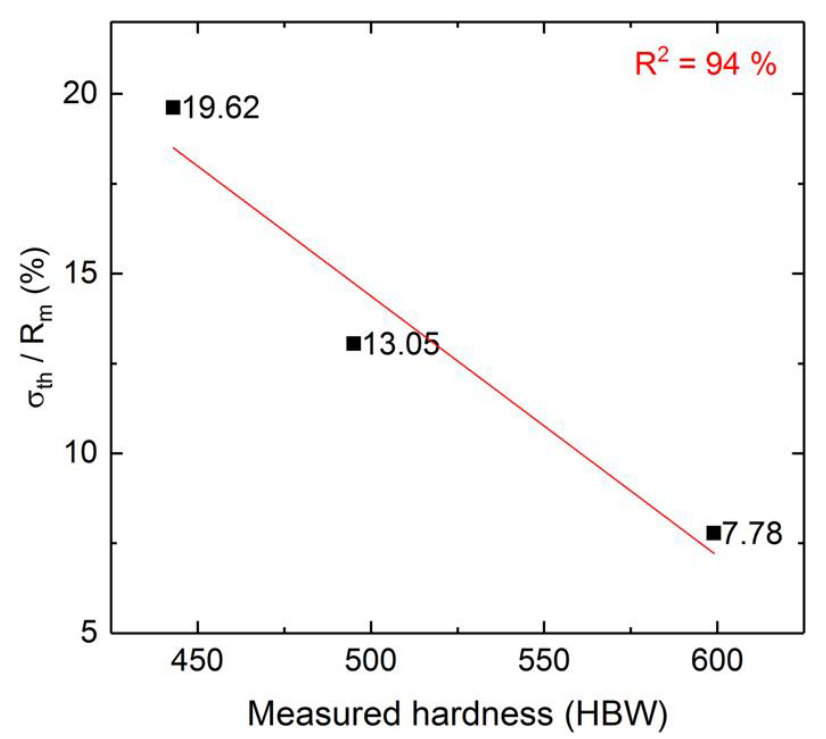

Figure 12. The relationship between relative threshold stress level $\left(\sigma_{\mathrm{th}} / \mathrm{R}_{\mathrm{m}}\right)$ and steel hardness.

Table 1. Chemical compositions (in wt.\%) and mechanical properties of the test materials.

\begin{tabular}{ccccccc}
\hline $\begin{array}{c}\text { Steel } \\
\text { grade (HBW) }\end{array}$ & $\mathrm{C}$ & $\mathrm{Si}$ & $\mathrm{Mn}$ & $\begin{array}{c}\text { Measured } \\
\text { hardness (HBW) }\end{array}$ & $\begin{array}{c}0.2 \% \text { offset } \\
\text { yield stress (MPa) }\end{array}$ & $\begin{array}{c}\text { Tensile } \\
\text { strength (MPa) }\end{array}$ \\
\hline 450 & 0.22 & 0.17 & 1.30 & 443 & 1193 & 1465 \\
500 & 0.26 & 0.21 & 1.14 & 495 & 1437 & 1629 \\
600 & 0.36 & 0.21 & 0.37 & 599 & 1756 & 2088 \\
\hline
\end{tabular}

Table 2. The summary of performed EDS analyses of fracture surfaces.

\begin{tabular}{|c|c|c|c|c|c|c|c|c|c|c|c|c|c|c|}
\hline $\begin{array}{l}\text { Average } \\
\text { from } 9 \\
\text { points }\end{array}$ & $\mathrm{O}-\mathrm{K}$ & Al-K & $\mathrm{Si}-\mathrm{K}$ & P-K & S-K & $\mathrm{Ca}-\mathrm{K}$ & $\mathrm{Cr}-\mathrm{K}$ & Mn-K & $\mathrm{Fe}-\mathrm{K}$ & $\mathrm{Br}-\mathrm{L}$ & Mo-L & $\mathrm{Cu}-\mathrm{K}$ & V-K & $\mathrm{Ni}-\mathrm{K}$ \\
\hline $\begin{array}{c}450 \\
(\mathrm{HBW})\end{array}$ & 2.71 & 0.23 & 0.29 & 0.13 & 0.25 & 0.22 & 0.30 & 1.56 & 94.22 & 0.47 & 0.53 & 0.00 & 0.00 & 0.00 \\
\hline $\begin{array}{c}500 \\
(\mathrm{HBW})\end{array}$ & 0.65 & 0.15 & 0.28 & 0.00 & 0.27 & 0.00 & 0.44 & 1.47 & 96.72 & 0.00 & 0.56 & 0.77 & 0.00 & 0.00 \\
\hline $\begin{array}{c}600 \\
(\mathrm{HBW})\end{array}$ & 0.98 & 0.24 & 0.26 & 0.11 & 0.40 & 0.19 & 0.42 & 0.63 & 95.60 & 0.00 & 0.42 & 0.37 & 0.13 & 1.05 \\
\hline
\end{tabular}

Table 3. The threshold stress level $\left(\sigma_{\mathrm{th}}\right)$ of each steel grade.

\begin{tabular}{cccc}
\hline Steel grade $(\mathrm{HBW})$ & Fracture $(\mathrm{MPa})$ & No fracture $(\mathrm{MPa})$ & Threshold stress $\sigma_{\text {th }}(\mathrm{MPa})$ \\
\hline 450 & 300 & 275 & 288 \\
500 & 225 & 200 & 213
\end{tabular}


WILEY-VCH 


\section{WILEY-VCH}

\section{Graphical Abstract}

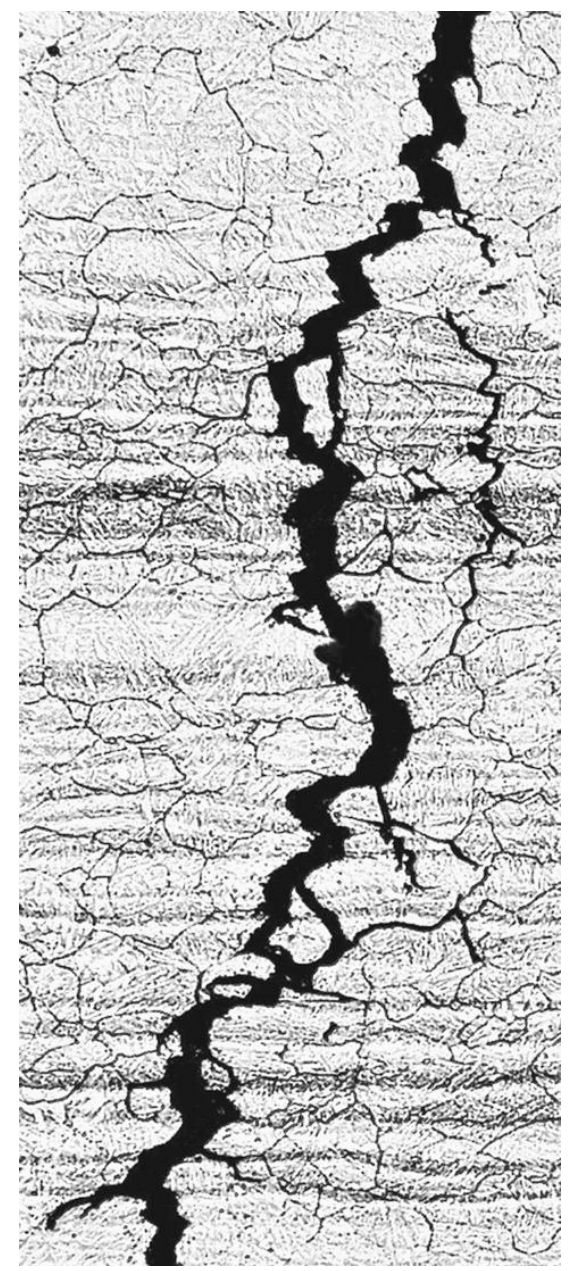

A novel testing method was developed to study the stress corrosion cracking susceptibility of high-strength steels. The susceptibility of direct-quenched abrasion-resistant steels was evaluated with relative threshold stress level, which was calculated as percentage of material-specific threshold stress level from the tensile strength. The results demonstrated a linear relationship between steel hardness and relative threshold stress level over the hardness range of $450-600$ HBW, where relative threshold stress level decreased with increasing hardness. 